\title{
Long Term Retention of Safe Diving Skills
}

Jennifer D Blitvich*, G Keith McElroy*, Brian A Blanksby", and Helen

E Parker $^{\#}$

* University of Ballarat

\# The University of Western Australia

Submitted to Journal of Science and Medicine in Sport
Initial submission:
July $17^{\text {th }} 2001$
Resubmitted incorporating reviewers’ changes:
June $16^{\text {th }}, 2002$
Resubmitted as second paper of two:
Nov $18^{\text {th }}, 2002$
Final Manuscript:
Jan $6^{\text {th }}, 2003$

Address for correspondence:

Dr Jenny Blitvich

School of Human Movement and Sport Sciences

University of Ballarat

PO Box 663

Ballarat, Victoria

Australia 3350

Email: j.blitvich@ballarat.edu.au

Phone: 0353279690

Fax: $\quad 0353279478$

Key Words: Shallow water diving; Spinal cord injury; Long term skill retention;

Word Count: 1669 (excluding heading and figure 'directions') 


\begin{abstract}
This short report describes a 20-month follow-up of safe diving skill, extending the 8-month retention period previously published in this journal. Thirty-four recreational swimmers with poor diving skills were evaluated before and immediately after a diving skills intervention program. Twenty-two returned for the eight-month follow-up evaluation and 16 returned 20 months post. As with the earlier study, Treadwater, Deck, Block and Running dives were videorecorded, and maximum depth, distance, velocity, entry angle and flight distance were compared. Underwater hand and arm positions were examined. Pre-intervention, a breaststroke arm action before maximum depth occurred in $18 \%$ of all dives and 38\% of Treadwater dives. This was eliminated post-intervention, improving head protection. The Treadwater dive elicited the greatest mean maximum depth, and ANOVA showed depth for this entry decreased (improved) following intervention and remained shallower at the eight-month and 20-month post follow-ups. The Block dive also became shallower following intervention while the Deck dive remained unchanged. As seven 10-minute skills sessions resulted in shallower dives with safer hand and arm positions, and these skills were retained over a 600 day non-practice period, it is reliable to consider that the inclusion of safe diving skills in learn-to-swim programs can provide a diving spinal cord injury prevention strategy.
\end{abstract}

Word Count: 204 


\section{Introduction $\quad\left(1^{\text {st }}\right.$ level heading $)$}

In the previous issue of this journal, the authors published a paper on retention of safe diving skills over an eight-month non-practice interval (1), illustrating maintenance of skills acquired through an intervention program designed to make diving safer among recreational swimmers with poor diving skills. Following intervention (2) swimmers performed shallower dives, with safer hand and arm positions. Improvements were retained over an eight-month non-practice period. This paper reports on a further follow-up, 20 months after initial intervention. A non-practice interval of 600 days is extremely rare. In a recent meta-analysis of retention literature (3), only 8\% of studies reviewed had a retention period more than 180 days. Retention over 600 days for a skill that can result in catastrophic injury when inappropriately performed highlights the value of learning safe diving skills.

\section{Methods $\left(1^{\text {st }}\right.$ level heading $)$}

\section{Participants $\quad\left(2^{\text {nd }}\right.$ level heading $)$}

Thirty-four, first year, university human movement majors (recreational swimmers, mean age 20.3 years, \pm 4.8 ) previously identified to have low diving skills participated in an intervention program to improve diving ability (2). All were invited for reassessment eight months after intervention (Post-8). To establish the permanence of changes, we now report on a further follow-up 20 months after intervention. The eightmonth retention interval corresponded with the approximate period between the end of one summer and the beginning of the next and represents a realistic non-practice period. Similarly, the 20-month interval corresponded with the commencement of the second summer. Twenty-two students attended Post-8, while 21 were present at Post-20. However, only 16 of these had attended Post-8. To ensure participants who attended the immediate Post data collection but not Post-8 or Post-20 were not statistically different from those who returned, t-tests were conducted comparing pre-intervention dive depths for these groups. 
The intervention program, (fully described in an earlier paper (2)), emphasised protecting the head with appropriate hand and arm position, and developed steering-up skills, to enable participants to stay shallower during the underwater pathway of their dives. The instructional cues "Lock hands”, “Lock head” and "Steer-up” were stressed throughout the intervention.

\section{Procedures $\left(2^{\text {nd }}\right.$ level heading $)$}

At each data collection, participants' dives were video-recorded for later analysis. One dive was performed from deck level, to tread water after surfacing (Treadwater), the typical entry for someone entering water in a recreation setting, to 'play'. Another deck level dive (Deck), and a dive from standard starting block height of $0.75 \mathrm{~m}$ (Block) were performed prior to swimming a length of the pool, simulating the circumstances of swimmers entering water to swim laps. Testing protocols were identical for each session. Maximum depth, distance at maximum depth, velocity at maximum depth, angle of entry and flight distance were measured. The number of participants whose hands separated, or were pulled back to expose the head during the dive, was recorded from underwater video film. Full details are provided elsewhere (2).

At Post-20, participants completed a survey reporting any diving experience which occurred in the retention interval.

For the 16 students who attended all four data collection sessions, a one-way repeated measures analysis of variance (ANOVA) with repeated measures on four levels was used for each variable at each diving condition. Where sphericity was not met, Greenhouse-Geisser correction was used. Where ANOVAs revealed significant main effects, simple contrasts and observed power were calculated to determine between which levels changes occurred. Traditional statistical analyses would recommend selection of an alpha level of .01 to control for experiment-wise error across multiple 
ANOVAs. However, comparisons also were made with significance set at .025 for all tests to guard against ignoring a meaningful result in the real world setting.

\section{Results $\quad\left(1^{\text {st }}\right.$ level heading $)$}

\section{Survey findings $\left(2^{\text {nd }}\right.$ level heading)}

The survey at Post-20 revealed that no participant had undertaken any formal swimming instruction since the intervention program concluded. Table 1 indicates frequency of swimming and number of dive entries typically performed in each session for study participants.

\section{***Please insert Table 1 about here}

Most participants had minimal 'diving practice’ post-intervention. Forty-three percent of respondents usually did not perform dive entries when swimming, 28.5\% usually performed one dive, while the remaining $28.5 \%$ performed two to five dives.

Participants were asked whether they heeded specific instructional cues used in class when performing dive entries. Fourteen percent considered the cues 'almost always', $62 \%$ 'sometimes' and 24\% 'almost never'. These findings, combined with $62 \%$ of respondents reporting swimming ‘about once a month’ or less, indicate they did not revise diving skill during the non-practice periods. At the eight-month data collection participants performed only one dive of each dive type and there was no reminder of instructional cues.

\section{Attrition ( $2^{\text {nd }}$ level heading)}

Results of the t-test comparing pre-intervention dive depths of students who attended both follow-ups with those who withdrew showed those who attended all data collections had a lower skill level prior to intervention $[\mathrm{t}(32)=2,250, p=.03$ ). Hence, 
results of the retention study could be considered to be robust, as the retention group was not more skilled than those who withdrew.

\section{Parameters $\left(2^{\text {nd }}\right.$ level heading $)$}

For this short report, results and discussion will concentrate on the major contributing factors to diving safety, maximum depth; and hand and arm position. Details of other parameters can be obtained directly from the corresponding author.

\section{Observational assessment of diving technique $\quad\left(2^{\text {nd }}\right.$ level heading)}

Observation of pre-intervention dives showed hands were not locked together on entry in $64 \%$ of dives(1). This fell to four percent at Post, increasing over the retention period to $11 \%$ at Post- 8 and $21 \%$ at Post-20. Arms were pulled backwards in a breaststrokelike arm action in $18 \%$ of all pre-intervention dives, and 38\% of Treadwater dives, leaving the head exposed and unprotected. This action was completely eliminated after intervention.

\section{Empirical analysis of diving technique $\left(2^{\text {nd }}\right.$ level heading $)$}

Means and standard deviations for measured parameters for the students who attended all four data collections are included in Table 2.

\section{***Please insert Table 2 about here***}

Results of ANOVAs are reported in Table 3. Observed power, effect size and simple contrasts are also included also.

Only 16 participants attended all four data collections, increasing the chance of an error of a null finding. In the ANOVA for Block condition, for two variables, the p value for main effect revealed a trend but did not reach significance (maximum depth $p=.086$, 
flight $p=.060$ ). To determine whether a larger sample size might have revealed significant results, additional ANOVAs were conducted, on three levels (Pre, Post and Post-20) with data added from five participants who attended Post-20 but not Post-8. Findings for these ANOVAs are included at the bottom of Table 3 and showed significant results for maximum depth $(p=.002)$. In summary, the Post-20 follow-up showed similar results to the Post-8 evaluation.

\section{***Please insert Table 3 about here***}

\section{Discussion $\quad\left(1^{\text {st }}\right.$ level heading $)$}

"Key factors for dive safety are hand and arm position, and dive depth. Locked hands and an extended arm position can protect the head from impact with the pool bottom or upslope, while shallow dives also help to minimise the risk of diving injury. Consistent application of these techniques is required to ensure the retention of safer diving skills.” (1, p???).

The complete eradication of the breaststroke-like arm action before or at maximum depth over the 20-month retention period is a crucial finding. If all recreational divers were to hold the arms extended beyond the head throughout the downward pathway of every dive entry, the likelihood of spinal injury from impact with the bottom would be small, as the hands would make first contact, protecting head and neck.

Throughout the study, there was relatively good retention of the initial improvements in the skill of locking the hands together. However, the number of participants who did not lock hands increased slightly over 20 months. Those who did not lock hands at Post-8 and Post-20 also did not lock hands pre-intervention, reinforcing the need to learn skills correctly in the initial learning phase, as making changes to already automated skills is frequently difficult. 
Depth is another critical factor in diving safety. The Treadwater dive was deepest and therefore most dangerous pre-intervention (4), and demonstrated the greatest decrease in depth after intervention. No significant changes occurred at Post-8 or Post-20 when compared to Post, indicating this safer technique was retained throughout the extended non-practice period. This finding is particularly important, as the typical circumstance of a diving spinal cord injury is when the injured person has entered the water for 'play' rather than to swim laps, hence performs a dive to treadwater.

The Block condition was the next deepest dive, pre-intervention. While statistical analysis of maximum depth for the 16 who attended all sessions failed to reach significance, further analysis of 21 participants attending Pre, Post and Post-20 showed a significant decrease in maximum depth following intervention which was retained at Post-20. Hence, depth results for Block for the 21 students who attended Post-20 followed the same pattern as the Treadwater dive for the 16 participants who attended all four data collections.

In the Deck condition, mean maximum depth did not decrease significantly with intervention. However, the deck dive was the most shallow and safe dive prior to intervention (0.52 $\mathrm{m}$ at the ear), so provided the least opportunity for improvement.

It is important to consider both declarative and procedural knowledge in motor skill learning and retention. Declarative knowledge refers to ability to verbally communicate how to perform a skill while procedural knowledge relates to ability to perform the skill $(5,6)$. The quantitative measurement included in the visual assessment and empirical analyses indicated robust performance (procedural knowledge). Declarative knowledge was indicated by the survey conducted at Post-20. Responses indicated a relatively high level of declarative knowledge, with $76 \%$ of participants reporting that they considered the cues 'almost always' or 'sometimes'. 
The long-term tracking of participants over the extended period of 600 days is extremely rare, reinforces the findings at eight months, and provides a strong indication of retention after a focused 'learn-to-dive’ program.

\section{Conclusion $\left(1^{\text {st }}\right.$ level heading $)$}

Maintenance of skills over an extended 20-month retention period further reinforces the merit of the safe diving intervention program evaluated in this research. The relatively short intervention (a total of 70 minutes of practice) has been shown to improve diving safety in low skilled participants, even after 20 months without practice. The incidence of diving spinal cord injury could be decreased if all recreational swimmers acquired the motor skills necessary to perform low risk dive entries and used these skills during every head first entry.

\section{References $\left(1^{\text {st }}\right.$ level heading $)$}

1. Blitvich JD, McElroy GK and Blanksby BA. Retention of safe diving skills. J Sci Med Sport 2003; ??(??).

2. Blitvich, JD, McElroy GK and Blanksby BA. Risk reduction in spinal cord injury: Teaching safe diving skills. J Sci Med Sport 2000; 3(2): 120-131.

3. Arthur, $\mathrm{W}$ et al. Factors that influence skill decay and retention: A quantitative review and analysis. Human Performance 1998; 11(1): 57-101.

4. Blitvich, JD et al. Characteristics of 'low risk' and 'high risk' divers by young adults: Risk reduction in spinal cord injury. Spinal Cord 1999; 37: 553-559.

5. Leonard, CT, The neuroscience of motor learning, in The neuroscience of human movement St Louis. Mosby. 1998

6. Wall, A et al. A knowledge-based approach to motor development: Implications for the physically awkward. Adapted Physical Activity Quarterly 1985; 2: 21-42. 


\section{Long Term Retention of Safe Diving}

Jennifer D Blitvich*, G Keith McElroy*, Brian A Blanksby*, and Helen E Parker

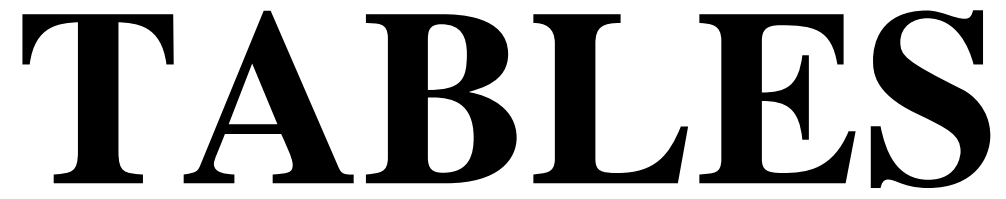

Address for correspondence:

Dr Jenny Blitvich

School of Human Movement and Sport Sciences

University of Ballarat

PO Box 663

Ballarat, Victoria

Australia 3350

Email: j.blitvich@ballarat.edu.au

Phone: 0353279690

Fax: 0353279478 
Table 1. Summary of Questionnaire Regarding Diving Practice After Intervention $(n=21)$

\begin{tabular}{lcccc}
\hline & \multicolumn{5}{c}{ Number of dive entries per swimming session } \\
How often have you been swimming? & None & $\mathbf{1}$ & $\mathbf{2 - 5}$ & $\mathbf{6 +}$ \\
\hline Most days & 0 & 0 & 0 & 0 \\
About once a week & 2 & 4 & 1 & 0 \\
About once a fortnight & 1 & 0 & 0 & 0 \\
About once a month & 2 & 2 & 2 & 0 \\
Less than once a month & 4 & 0 & 3 & 0 \\
Less than once a year & 0 & 0 & 0 & 0 \\
\hline Total & $\mathbf{9}$ & $\mathbf{6}$ & $\mathbf{6}$ & $\mathbf{0}$ \\
\hline
\end{tabular}


Table 2. Means, Standard Deviations and Ranges for the 16 Participants Who Completed All Testing Sessions

\begin{tabular}{|c|c|c|c|c|c|c|c|c|c|c|c|c|c|}
\hline VARIABLE & & \multicolumn{4}{|c|}{$\begin{array}{c}\text { TREADWATER } \\
\mathrm{N}=16\end{array}$} & \multicolumn{4}{|c|}{$\begin{array}{l}\text { DECK } \\
\mathrm{N}=16\end{array}$} & \multicolumn{4}{|c|}{$\begin{array}{c}\text { BLOCK } \\
\mathrm{N}=16 \\
\end{array}$} \\
\hline \multirow[t]{4}{*}{ Maximum depth (m) } & Min & $\begin{array}{l}\text { Pre } \\
0.58\end{array}$ & $\begin{array}{l}\text { Post } \\
0.18\end{array}$ & $\begin{array}{l}\text { Post } 8 \\
0.30\end{array}$ & $\begin{array}{l}\text { Post } 20 \\
0.22\end{array}$ & $\begin{array}{l}\text { Pre } \\
0.14\end{array}$ & $\begin{array}{l}\text { Post } \\
0.14\end{array}$ & $\begin{array}{l}\text { Post } 8 \\
0.14\end{array}$ & $\begin{array}{l}\text { Post } 20 \\
0.20\end{array}$ & $\begin{array}{l}\text { Pre } \\
0.30\end{array}$ & $\begin{array}{l}\text { Post } \\
0.32\end{array}$ & $\begin{array}{l}\text { Post } 8 \\
0.28\end{array}$ & $\begin{array}{l}\text { Post } 20 \\
0.28\end{array}$ \\
\hline & Max & 1.40 & 0.98 & 0.86 & 0.92 & 0.96 & 0.72 & 0.68 & 0.78 & 1.18 & 0.84 & 1.18 & 1.02 \\
\hline & Mean & 0.85 & 0.57 & 0.52 & 0.50 & 0.52 & 0.48 & 0.42 & 0.47 & 0.70 & 0.52 & 0.55 & 0.57 \\
\hline & SD & 0.24 & 0.22 & 0.16 & 0.17 & 0.18 & 0.15 & 0.13 & 0.15 & 0.26 & 0.14 & 0.21 & 0.20 \\
\hline \multirow{4}{*}{$\begin{array}{l}\text { Maximum distance to } \\
\text { maximum depth (m) }\end{array}$} & Min & 2.62 & 2.84 & 2.76 & 3.06 & 3.25 & 2.76 & 2.66 & 2.66 & 3.35 & 3.18 & 2.94 & 2.92 \\
\hline & Max & 4.35 & 4.86 & 4.18 & 4.14 & 4.28 & 4.14 & 3.86 & 4.64 & 4.96 & 4.56 & 4.62 & 4.96 \\
\hline & Mean & 3.48 & 3.65 & 3.47 & 3.58 & 3.63 & 3.64 & 3.54 & 3.54 & 4.22 & 4.01 & 3.94 & 3.98 \\
\hline & SD & 0.41 & 0.52 & 0.33 & 0.32 & 0.36 & 0.35 & 0.32 & 0.42 & 0.43 & 0.43 & 0.43 & 0.55 \\
\hline \multirow{4}{*}{$\begin{array}{l}\text { Velocity at maximum } \\
\text { depth }(\mathrm{m} / \mathrm{s})\end{array}$} & Min & 0.92 & 1.44 & 1.06 & 1.51 & 1.42 & 1.56 & 1.67 & 1.45 & 1.31 & 2.22 & 1.73 & 1.58 \\
\hline & Max & 2.47 & 3.28 & 3.03 & 2.73 & 2.63 & 3.14 & 3.25 & 2.80 & 3.61 & 3.36 & 3.50 & 3.13 \\
\hline & Mean & 1.95 & 2.26 & 2.30 & 1.96 & 2.12 & 2.45 & 2.52 & 2.16 & 2.28 & 2.88 & 2.87 & 2.57 \\
\hline & SD & 0.39 & 0.53 & 0.53 & 0.34 & 0.38 & 0.43 & 0.36 & 0.36 & 0.62 & 0.28 & 0.45 & 0.45 \\
\hline \multirow{4}{*}{$\begin{array}{l}\text { Angle of entry } \\
\text { (degrees) }\end{array}$} & Min & 22 & 6 & 16 & 7 & 0 & 10 & 11 & 5 & 4 & 18 & 22 & 15 \\
\hline & Max & 59 & 51 & 55 & 53 & 50 & 36 & 47 & 56 & 45 & 46 & 49 & 56 \\
\hline & Mean & 38 & 28 & 32 & 31 & 28 & 23 & 27 & 29 & 33 & 31 & 36 & 38 \\
\hline & SD & 10 & 11 & 10 & 13 & 11 & 8 & 9 & 14 & 10 & 7 & 8 & 12 \\
\hline \multirow[t]{4}{*}{ Flight distance (m) } & Min & 1.82 & 1.90 & 1.84 & 1.92 & 2.00 & 1.98 & 2.00 & 1.72 & 2.10 & 2.26 & 2.00 & 2.06 \\
\hline & Max & 2.80 & 2.58 & 2.96 & 2.86 & 2.92 & 2.66 & 2.94 & 3.00 & 3.34 & 3.38 & 3.34 & 3.54 \\
\hline & Mean & 2.09 & 2.28 & 2.33 & 2.44 & 2.31 & 2.36 & 2.50 & 2.51 & 2.72 & 2.76 & 2.84 & 2.92 \\
\hline & SD & 0.23 & 0.22 & 0.26 & 0.30 & 0.25 & 0.21 & 0.29 & 0.34 & 0.35 & 0.30 & 0.39 & 0.38 \\
\hline
\end{tabular}


Table 3. ANOVA Results for Pre, Post, Post 8, Post 20 Comparing Results to Pre and Post (n=16)

\begin{tabular}{|c|c|c|c|c|c|c|c|c|c|c|c|c|c|c|c|c|c|c|c|}
\hline Dive & Dependent Measure & $\begin{array}{l}\text { Main } \\
\text { Effect }\end{array}$ & $\begin{array}{c}\text { Observed } \\
\text { Power }^{\mathrm{a}}\end{array}$ & $\begin{array}{c}\text { Eta } \\
\text { Squared }\end{array}$ & $\begin{array}{l}\text { Pre - } \\
\text { Post }\end{array}$ & $\begin{array}{c}\text { Observed } \\
\text { Power }^{\mathrm{a}}\end{array}$ & $\begin{array}{c}\text { Eta } \\
\text { Squared }\end{array}$ & $\begin{array}{c}\text { Pre - } \\
\text { Post } 8 \\
\end{array}$ & $\begin{array}{c}\text { Observed } \\
\text { Power }^{\mathrm{a}}\end{array}$ & $\begin{array}{c}\text { Eta } \\
\text { Squared }\end{array}$ & $\begin{array}{l}\text { Pre- } \\
\text { Post } 20 \\
\end{array}$ & $\begin{array}{l}\text { mple Cont } \\
\text { Observed } \\
\text { Power }^{{ }^{2}}\end{array}$ & $\begin{array}{l}\text { Sts } \\
\text { Eta } \\
\text { Squared }\end{array}$ & $\begin{array}{l}\text { Post - } \\
\text { Post } 8 \\
\end{array}$ & $\begin{array}{c}\text { Observed } \\
\text { Power }^{\mathrm{a}}\end{array}$ & $\begin{array}{c}\text { Eta } \\
\text { Squared }\end{array}$ & $\begin{array}{c}\text { Post - } \\
\text { Post } 20 \\
\end{array}$ & $\begin{array}{c}\text { Observed } \\
\text { Power }^{\mathrm{a}} \\
\end{array}$ & $\begin{array}{c}\text { Eta } \\
\text { Squared }\end{array}$ \\
\hline \multirow{4}{*}{$\begin{array}{c}\text { Treadwater } \\
(\mathrm{n}=16)\end{array}$} & Maximum depth & $.000^{*}$ & .999 & .564 & $.002^{*}$ & .940 & .486 & $.000^{*}$ & 1.000 & .707 & $.000^{*}$ & 1.000 & .812 & .266 & .191 & .082 & .250 & .202 & .087 \\
\hline & $\begin{array}{l}\text { Distance at max. depth } \\
\text { Velocity at max. depth }\end{array}$ & $\begin{array}{l}.370 \\
.041\end{array}$ & .205 & $\begin{array}{l}.064 \\
.458\end{array}$ & & & & & & & & & & & & & & & \\
\hline & Entry angle & $.019 *$ & .782 & .522 & $.002 *$ & .948 & .496 & $.016^{*}$ & .717 & .329 & $.025 *$ & .645 & 293 & .070 & .446 & .202 & .095 & .386 & .175 \\
\hline & Flight distance & $.001 *$ & .994 & .731 & $.001 *$ & .957 & .509 & $.000^{*}$ & .997 & .635 & $.000^{*}$ & .997 & .629 & .314 & .164 & .067 & $.018^{*}$ & .697 & .319 \\
\hline \multirow{5}{*}{$\begin{array}{l}\text { Deck } \\
\qquad(\mathrm{n}=16)\end{array}$} & Maximum depth & .149 & .372 & .121 & & & & & & & & & & & & & & & \\
\hline & Distance at max. depth & .351 & 248 & 216 & & & & & & & & & & & & & & & \\
\hline & Velocity at max. depth & $.005 *$ & .917 & .611 & $.001^{*}$ & .964 & .519 & $.002^{*}$ & .944 & .490 & .748 & .061 & .013 & .315 & .164 & .067 & $.006 *$ & .845 & .404 \\
\hline & Entry angle & .127 & .449 & .345 & & & & & & & & & & & & & & & \\
\hline & Flight distance & $.016 *$ & .810 & .538 & .245 & .205 & .089 & $.002 *$ & .930 & .475 & $.004 *$ & .887 & .435 & $.005^{*}$ & 871 & .422 & $.014 *$ & .735 & .338 \\
\hline \multirow{5}{*}{$\begin{array}{l}\text { Block } \\
\quad(\mathrm{n}=16)\end{array}$} & Maximum depth & .086 & .526 & .378 & & & & & & & & & & & & & & & \\
\hline & Distance at max. depth & .113 & .403 & 359 & & & & & & & & & & & & & & & \\
\hline & Velocity at max. depth & $.002 *$ & .970 & .670 & $.001 *$ & .982 & .557 & $.000^{*}$ & .989 & .580 & .027 & .628 & .346 & .926 & .051 & .001 & $.005^{*}$ & .861 & .414 \\
\hline & Entry angle & $.016 *$ & .687 & .203 & .416 & .123 & .045 & .152 & .293 & .132 & .119 & .340 & .154 & $.000^{*}$ & .996 & .617 & $.014^{*}$ & .741 & .341 \\
\hline & Flight distance & .060 & .595 & .423 & & & & & & & & & & & & & & & \\
\hline $\begin{array}{l}\text { Block } \\
(n=21)\end{array}$ & Maximum depth & $.002^{*}$ & .911 & .300 & $.004^{*}$ & .882 & .334 & & & & .008* & .882 & .354 & & & & . 1866 & .256 & .086 \\
\hline
\end{tabular}

*significant at $p<0.025$

*significant at $p<0.025$
a Observed Power computed using alpha $=.025$ 
Long term retention of safe diving 